\section{Hypertriglyceridaemia-induced pancreatitis prompted by acute corticosteroid treatment: caution for clinicians}

We report two novel cases of hypertriglyceridaemiainduced pancreatitis induced by corticosteroid taper. Both patients had known dyslipidaemias and were later referred to the University of Michigan Lipid Management Clinic unaware of the risks of corticosteroids in their condition. ${ }^{1}$ These cases highlight the need to be cognisant that even short-term corticosteroids can precipitate hypertriglyceridaemia-induced pancreatitis in susceptible individuals.

Characteristics of the two patients are summarised in Table 1 . Patient 1 is a 41 -year-old woman with underlying type-IV hyperlipidaemia who presented to the emergency department for urticaria after poison oak exposure and was discharged on a 10-day course of prednisone $(60 \mathrm{mg} \times 1 \mathrm{~d}$, $40 \mathrm{mg} \times 5 \mathrm{~d}$ and $20 \mathrm{mg} \times \mathrm{l} \mathrm{d}$ ). Four days after beginning her corticosteroid taper, she was hospitalised for acute-onset abdominal pain. Triglycerides $(49.0 \mathrm{mmol} / \mathrm{L})$ and lipase (7.45 $\mu \mathrm{kat} / \mathrm{L}$ ) were elevated, and computed tomography of the abdomen/pelvis confirmed acute pancreatitis. She denied recent illness or changes in diet, alcohol, medications or blood glucose. Triglycerides immediately prior to treatment were unknown; her most recent triglycerides were $2.88 \mathrm{mmol} / \mathrm{L}$ on gemfibrozil $600 \mathrm{mg}$ twice daily, measured 13 days prior to her admission to the hospital. Neither the patient nor her inpatient team realised the trigger of her pancreatitis until a retrospective chart review in lipid clinic follow-up several months later.

Patient 2 is a 54-year-old woman with a history of type- $\mathrm{V}$ hyperlipidaemia and two previous episodes of hypertriglyceridaemia-induced pancreatitis, beginning at age 47. She developed a chronic obstructive pulmonary disease exacerbation and was prescribed a 7-day course of prednisone $50 \mathrm{mg}$ daily. While completing her corticosteroid burst treatment (exact date of prednisone prescription unknown), she developed acute-onset abdominal pain and presented to the emergency department, where she had elevated levels of amylase (15.2 $\mu \mathrm{kat} / \mathrm{L})$, lipase (46.1 $\mu \mathrm{kat} / \mathrm{L})$ and triglycerides $(72.4 \mathrm{mmol} / \mathrm{L})$. Triglyceride levels from 2 months prior to her admission to the hospital were $7.96 \mathrm{mmol} / \mathrm{L}$ on fenofibrate nanocrystals
$145 \mathrm{mg}$ once daily. She endorsed recent decreased oral intake, but otherwise denied any changes in alcohol, medications or blood glucose. No linkage between corticosteroids and hypertriglyceridaemia-induced pancreatitis was considered by her inpatient team.

Differential diagnosis for chylomicron syndrome precipitation in patients with underlying dyslipidaemias include poor diet and/or fat intake, alcohol use, noncompliance with medications, pregnancy and/or worsening diabetes control, systemic oestrogen use, and

Table 1 Baseline characteristics and testing results on presentation for acute pancreatitis

\begin{tabular}{|c|c|c|}
\hline & Patient 1 & Patient 2 \\
\hline $\begin{array}{l}\text { Baseline } \\
\text { characteristics }\end{array}$ & $\begin{array}{l}\text { 41-year-old woman, } \\
\text { DM, PCOS }\end{array}$ & $\begin{array}{l}\text { 54-year-old woman, } \\
\text { DM, COPD }\end{array}$ \\
\hline $\mathrm{BMI}\left(\mathrm{kg} / \mathrm{m}^{2}\right)$ & 27.9 & 28.5 \\
\hline $\begin{array}{l}\text { Frederickson } \\
\text { phenotype }\end{array}$ & Type IV & $\begin{array}{l}\text { Type IV } \\
\text { (prior history of } \\
\text { type V) }\end{array}$ \\
\hline \multicolumn{3}{|l|}{ Baseline lipid profile $\dagger$} \\
\hline $\begin{array}{c}\text { Total cholesterol } \\
\mathrm{mmol} / \mathrm{L}\end{array}$ & 5.43 & 7.37 \\
\hline $\begin{array}{l}\text { Triglycerides } \\
\text { (mmol/L) }\end{array}$ & 2.88 & 7.96 \\
\hline $\begin{array}{l}\text { Lipid-lowering } \\
\text { medications: }\end{array}$ & $\begin{array}{l}\text { Gemfibrozil } 600 \text { mg } \\
\text { BID }\end{array}$ & $\begin{array}{l}\text { Fenofibrate } \\
\text { nanocrystals } \\
145 \text { mg q-day }\end{array}$ \\
\hline $\begin{array}{l}\text { Other relevant } \\
\text { medications }\end{array}$ & $\begin{array}{r}\text { Oestrogen OCP, insulin } \\
\text { detemir, dapagliflozin }\end{array}$ & \\
\hline $\begin{array}{l}\text { Prior pancreatitis } \\
\text { Acute presentation }\end{array}$ & No & Twice \\
\hline $\begin{array}{r}\text { Corticosteroid } \\
\text { indication }\end{array}$ & Urticarial rash & COPD flare \\
\hline Amylase ( $\mu$ kat/L) & - & 15.2 \\
\hline Lipase ( $\mu$ kat/L) & 7.45 & 46.1 \\
\hline $\begin{array}{l}\text { Triglycerides } \\
\text { (mmol/L) }\end{array}$ & 49.0 & 72.4 \\
\hline CT scan findings & $\begin{array}{l}\text { Acute uncomplicated } \\
\text { pancreatitis }\end{array}$ & Not documented \\
\hline
\end{tabular}

$\dagger$ Documented within 1 month prior to their acute pancreatitis episode. $\ddagger$ Neither patient was on other lipid-altering medications (e.g. statins, fish oils) at the time of their acute pancreatitis episode. BID, twice a day; BMI, body mass index; COPD, chronic obstructive pulmonary disease; DM, diabetes mellitus type 2, q-day, once daily; OCP, oral contraceptive pills; PCOS, polycystic ovary syndrome. 
rarely, hypothyroidism or nephrotic syndrome. As noted above, both patients denied these factors as precipitants of their acutely elevated triglyceride levels and resulting pancreatitis. Calculation of the Naranjo Adverse Drug Reaction (ADR) Probability Scale ${ }^{2}$ resulted in a score of 5 (Supporting Information Appendix S1), indicating a 'probable' ADR due to corticosteroid use due to the reasonable temporal sequence and lack of alternative reasonable causes of pancreatitis. We note that although it is 'probable' by the Naranjo scale that corticosteroids caused acute pancreatitis in these two patients, this score is artificially low due to the lack of: (i) prior conclusive case reports in the dyslipidaemic population; (ii) trials of prednisone discontinuation/ dose reduction/re-administration; (iii) antagonist or placebo administration; and (iv) prednisone blood level measurement.

Studies of patients without known dyslipidaemias note an increase in triglyceride levels with chronic corticosteroid use. Of note, triglyceride levels on average were $<2 \mathrm{mmol} / \mathrm{L}^{3}{ }^{3}$ making corticosteroid-induced pancreatitis unlikely in a non-dyslipidaemic population. ${ }^{4}$ In contrast, the lipid-altering effects of corticosteroids in patients with baseline hypertriglyceridaemia are poorly described. Despite the theoretical linkage, we are unaware of prior reports of a brief course of oral corticosteroids being implicated as the sole trigger of hypertriglyceridaemia-induced pancreatitis, except in chemotherapy patients. ${ }^{1}$ Unfortunately, neither our patients nor their healthcare providers realised recent corticosteroid usage was a potential trigger for pancreatitis. We acknowledge that our diagnoses were made by retrospective histories/chart reviews; however, the temporal course of events strongly support our conclusions, as noted by a Naranjo scale of 5, indicating a 'probable' ADR despite a likely underestimated score due to numerous 'do not know' responses.
These cases show that a short-term course of oral corticosteroids has the potential to trigger hypertriglyceridaemia-induced pancreatitis in susceptible patients. While no evidence-based algorithm exists, several prudent recommendations can be made. Foremost, hyperlipidaemic patients should be educated about the risks. If treatment is required, providers should obtain baseline triglyceride and glucose levels, control underlying factors (e.g. diet, alcohol and diabetes), reduce/discontinue other offending medications (e.g. oral oestrogens), and carefully monitor triglycerides. If triglycerides increase $>11 \mathrm{mmol} / \mathrm{L}$, discontinuation of oral corticosteroids should be strongly considered. ${ }^{5}$ The benefits of starting/intensifying triglyceride-lowering medications (e.g. fibrates, eicosapentaenoic acid/docosahexaenoic acid) before/during therapy and/or prophylactic apheresis in severe cases remain unknown. Finally, we recommend against prescribing corticosteroids if baseline triglycerides are $>5.5 \mathrm{mmol} / \mathrm{L},{ }^{5}$ unless required for a life-threatening illness. In conclusion, these cases highlight the importance that healthcare providers and patients alike be aware of the potential dangers of oral corticosteroid treatment among individuals with dyslipidaemias.

\section{Acknowledgements}

All authors had access to patient data and participated in writing and revision of the manuscript.

Received 22 April 2018; accepted 21 June 2018.

Daniel Seung Kim (iD, Patrick J. O'Hayer,

Melvyn Rubenfire and Robert D. Brook Division of Cardiovascular Medicine, Department of Internal Medicine, University of Michigan, Ann Arbor, Michigan, USA

Funding: University of Michigan Cardiovascular Center Inaugural Grant. D. S. Kim was supported by AHA 16POST27250048.

\section{References}

1 Vodnala D, Rubenfire M, Brook RD. Secondary causes of dyslipidemia. Am J Cardiol 2012; 110: 823-5.

2 Naranjo CA, Busto U, Sellers EM, Sandor P, Ruiz I, Roberts EA et al. A method for estimating the probability of adverse drug reactions. Clin Pharmacol Ther 1981; 30: 239-45.

3 Fardet L, Cabane J, Kettaneh A, Lebbe C, Flahault A. Corticosteroid-induced lipodystrophy is associated with features of the metabolic syndrome. Rheumatology 2007; 46: 1102-6.
4 Steinberg WM, Lewis JH. Steroidinduced pancreatitis: does it really exist? Gastroenterology 1981; 81: 799-808.

5 Lindkvist B, Appelros S, Regnér S, Manjer J. A prospective cohort study on risk of acute pancreatitis related to serum triglycerides, cholesterol and fasting glucose. Pancreatology 2012; 12: 317-24.

\section{Supporting Information}

Additional supporting information may be found in the online version of this article at the publisher's web-site:

Appendix S1. Adverse drug reaction probability scale. 